RECENT ADVANCES

\title{
Recent advances in congenital diaphragmatic hernia
}

\author{
N P Smith, E C Jesudason, N C Featherstone, H J Corbett, P D Losty
}

Arch Dis Child 2005;90:426-428. doi: 10.1136/adc.2003.045765

Congenital diaphragmatic hernia $(C D H)$ is a common birth defect which continues to challenge paediatric surgeons and intensivists. Affecting approximately 1:2500 births, a baby with CDH is born every 24-36 hours in the UK.'

$\ldots \ldots \ldots \ldots \ldots \ldots \ldots \ldots$ or the majority of newborns in whom $\mathrm{CDH}$ is an isolated anomaly, the degree of associated pulmonary hypoplasia remains the major determinant of survival. Recent "single institution" reports have shown encouraging results, with survival figures exceeding $80 \%{ }^{2-4}$ However, these should be recognised as reports on live-borns arriving at a specialist centre. There is no doubt that a significant proportion of cases continue to succumb either antenatally or in the first few hours of life. ${ }^{5}$ Interestingly the earliest reports of surgery for $\mathrm{CDH}$ showed survival figures similar to the recent successful outcomes from specialist centres. ${ }^{6}$ This was a reflection of natural patient selection; neonates operated on in early series were those who had survived the first crucial minutes and hours-that is, those least affected by pulmonary hypoplasia and hypertension. Improved resuscitation and neonatal critical care has resulted in a very different patient population reaching surgery. It has taken more than 50 years to regain these impressive survival figures with more challenging patients.

\section{CURRENT TREATMENT STRATEGIES: EVIDENCE BASE}

Advances in neonatal intensive care and ventilation have greatly improved the outlook for liveborn infants with $\mathrm{CDH}$. The introduction of ventilatory adjuncts such as high frequency oscillatory ventilation, inhaled nitric oxide, and extracorporeal membrane oxygenation (ECMO) are supported by several anecdotal reports. However, these interventions have not shown true survival benefits for $\mathrm{CDH}$ in randomised trials. Inhaled nitric oxide has been the subject of a Cochrane review in term or near term infants with respiratory failure. This report concluded that the use of nitric oxide could be supported in general for infants with pulmonary hypertension and respiratory failure. However, benefit was not seen for patients with $\mathrm{CDH}$; the review further noted that some reports have indicated a worse outcome in this group. ${ }^{7}$ A large randomised trial focused solely on $\mathrm{CDH}$ may resolve this issue.

High frequency oscillatory ventilation (HFOV) has been analysed by the Cochrane group for its efficacy as a "rescue" therapy for babies in whom conventional ventilatory strategies fail. The report found only one randomised trial which included infants with a wide variety of respiratory pathology. This trial showed no benefit for HFOV compared to conventional ventilation. $^{8}$ Reports from single institutions continue to extol the benefits of HFOV in newborns with $\mathrm{CDH}$, in particular when this is used as an elective ventilatory strategy. ${ }^{9}{ }^{10}$ A large multicentre trial is needed to address this question.

ECMO as therapy for newborns with respiratory failure became widely available during the 1980s. Its potential benefits were tested in the UK by a collaborative prospective randomised trial. The trial failed to show improved outcomes for $\mathrm{CDH}$, however entry criteria have been criticised as being severely stringent-necessitating "near unsalvageable" respiratory failure before recruitment. ${ }^{11}$ A subsequent Cochrane review on the use of ECMO in neonates identified four randomised trials, of which two included infants with CDH. This review commented that survival benefit is seen for all newborns-but is least evident in CDH. Longer term follow up data are needed to assess ongoing morbidity and mortality in this severely affected group of patients. ${ }^{12}$ The UK ECMO group have recently highlighted these issues, showing that at 67 months median follow up only 7/73 children ( $10 \%)$ are free of significant neurodevelopmental delay, and medical and surgical intervention. ${ }^{13}$ Long term follow up is warranted for all patients with $\mathrm{CDH}$, not merely those who have been treated with ECMO. Close attention to $\mathrm{CDH}$ survivors reveals a high incidence of long term morbidity, particularly focused on the respiratory and gastrointestinal systems. ${ }^{14}{ }^{15}$ Specialist multidisciplinary clinics are evolving in many centres, including Liverpool, to provide dedicated care for the needs of these vulnerable patients.

Barotrauma has now been recognised as a significant cause of mortality and morbidity in CDH. ${ }^{16}$ The concept of "gentle" ventilation/ permissive hypercapnia was proposed by Wung and colleagues at Columbia University, New York in the 1980s. ${ }^{17}$ The protocol is designed to minimise barotrauma by strictly limiting the peak inflation pressure. Ventilation is aimed at keeping pre-ductal oxygen saturations above $85 \%$, while tolerating rises in $\mathrm{PaCO}_{2}$. Survival figures $>80 \%$ have been reported from New York and Boston. ${ }^{4}{ }^{18}$ This represents one of the biggest single advances in $\mathrm{CDH}$ care in recent years and has led to declining use of ECMO.

Delayed surgical repair of $\mathrm{CDH}$ following a period of preoperative stabilisation is generally employed in most centres. Few paediatric surgeons support emergent repair. ${ }^{19}$ This approach

Abbreviations: $\mathrm{CDH}$, congenital diaphragmatic hernia; ECMO, extracorporeal membrane oxygenation; HFOV, high frequency oscillatory ventilation 
permits full assessment and stabilisation of labile physiology. Increasingly cardiologists can play a pivotal role in serial echocardiographic assessment to monitor ductal shunting and pulmonary hypertension. A team approach is crucial to guide the optimum timing of surgery, a strategy currently employed at our institution and other specialist centres. Operation via a subcostal incision gives access to the diaphragm where primary repair following visceral reduction or a prosthetic implant may be needed to close the defect. There is however a high rate of patch disruption/herniation with artificial prostheses as the patients grow. ${ }^{20}$ Recent interest has therefore focused on the use of bio-prostheses ${ }^{21}$ in an effort to provide a "scaffold" that grows with the patient. Laparoscopy has been utilised in selected cases to repair $\mathrm{CDH}$. Caution should be exercised in high risk newborns. ${ }^{22}$

\section{HIDDEN MORTALITY AND "TRUE" OUTCOMES}

One should be sceptical when interpreting studies on $\mathrm{CDH}$ that report excellent survival. Such reports may include selection bias and fail to recognise "hidden mortality" has been shown by recent communications from both Newcastle, UK and Ontario, Canada. ${ }^{524}$ A controversial area which has been highlighted is the difference in survival between infants treated in "high volume" and "low volume" centres. In two studies published this year, "high volume" centres (treating more than five or six cases per year) performed significantly better. ${ }^{25}{ }^{26}$ Is there a case for $\mathrm{CDH}$ management being designated to specialist centres in the UK?

\section{FETAL THERAPIES: WHERE ARE WE NOW?}

For over two decades pioneering efforts have been deployed to rescue lung growth in the severely affected fetus with $\mathrm{CDH}$. The work of Harrison's group in San Francisco initially focused on open antenatal repair of the diaphragmatic defect. ${ }^{27}$ Outcomes were hampered by technical surgical difficulties, problems maintaining tocolysis, and a high rate of preterm delivery. Further advances resulted from the key observation that babies born with congenital laryngeal atresia (preventing the normal efflux of intraluminal lung liquid) develop tremendous pulmonary growth. ${ }^{28}$ This finding prompted the concept that occluding the fetal trachea (the "PLUG" (plug the lung until it grows) procedure) in pulmonary hypoplasia associated with $\mathrm{CDH}$ could increase lung growth and improve outcomes. Initial attempts at open tracheal occlusion were succeeded by a modified endoscopic technique-so-called FETENDO (FETal ENDOscopic) surgery. ${ }^{29}$ A National Institute of Health sponsored randomised trial led by the San Francisco group disappointingly showed no survival benefits compared to elective delivery at specialist centres with optimal postnatal $\mathrm{CDH}$ care. The trial was terminated early by the steering committee due to unexpectedly good outcomes in the control group. ${ }^{30}$ In Europe fetal tracheal occlusion (FETO) continues to be explored-further technical refinement may uncover survival benefits in high risk patients. ${ }^{31}$

The issue of determining accurate antenatal prognostic markers has proven problematic throughout these ground breaking studies. The ability to detect those fetuses most severely affected in the prenatal period would be invaluable in selecting those for high risk interventions. Despite a wide variety of indices being suggested, there is as yet no robust marker to determine accurate prognosis. Attention has focused on the lung:head ratio (LHR); calculating the ratio between cross-sectional lung area (contralateral to the defect) and head circumference. The original description of the technique from Harrison's group found that an LHR $<0.6$ was universally fatal; in subsequent studies this has been modified to $<1.0$. Larger prospective studies are required to validate these observations. ${ }^{32} 33$ It is vital that paediatric surgeons are involved with obstetricians and neonatologists in the counselling process for all prenatally diagnosed $\mathrm{CDH}$ cases. Outcomes are steadily improving in those centres with a specialist interest in this birth defect. ${ }^{434}$

\section{BASIC SCIENCE: TRANSLATIONAL RESEARCH}

Improved understanding of normal and abnormal lung development may lead to new therapeutic targets for lung hypoplasia and the associated lethal pulmonary hypertension. Progress in developmental biology has uncovered a host of genetic and growth factor/cell signalling pathways involved in early branching morphogenesis, many of which are disturbed in experimental models of $\mathrm{CDH}$ and pulmonary hypoplasia. ${ }^{135-37} \mathrm{~A}$ number of syndromes are identified in CDH (for example, Fryn's syndrome); these are often accompanied by other extensive and life threatening defects. ${ }^{38}{ }^{39}$ No specific causal gene(s) defects have been identified in humans; screening studies are underway to identify likely candidates (PK Donahoe and JJ Schnitzer, personal communication).

The importance of mechanical factors in regulating lung development has been shown through work on the tracheal PLUG, the role of lung liquid and studies on fetal breathing movements. ${ }^{40}{ }^{41}$ Further advances may arise from improved understanding of primitive events regulating airway physiology-lung growth. ${ }^{42}$ The mechanisms underlying abnormal pulmonary vascular development are undergoing significant scrutiny. ${ }^{43}$ Basic science studies have also illustrated the potential benefits of antenatal corticosteroid therapy in experimental $\mathrm{CDH}^{44}$ As improved outcomes are steadily unfolding, a clinical trial is warranted to test this therapy in the most severely affected fetus with CDH. Selecting these patients remains a challenge for ongoing studies. The goal for quality research in $\mathrm{CDH}$ is to translate experimental observations into clinically safe and effective therapies. Such efforts will be significantly aided by ongoing collaboration between dedicated researchers with the international $\mathrm{CDH}$ Study Group ${ }^{45}$ and the interplay with active parent support groups such as CHERUBS.

\section{Authors' affiliations}

N P Smith, E C Jesudason, N C Featherstone, H J Corbett, P D Losty, Department of Paediatric Surgery, Royal Liverpool Children's Hospital (Alder Hey) and The Department of Child Health, University of Liverpool, UK

Competing interests: none declared

\section{REFERENCES}

1 Smith NP, Jesudason EC, Losty PD. Congenital diaphragmatic hernia. Paediatr Respir Rev 2002;3:339-48.

2 Al-Shanafey S, Giacomantonio M, Henteleff H. Congenital diaphragmatic hernia: experience without extracorporeal membrane oxygenation. Pediatr Surg Int 2002;18:28-31.

3 Bagolan P, Casaccia G, Crescenzi F, et al. Impact of a current treatment protocol on outcome of high-risk congenital diaphragmatic hernia. J Pediatr Surg 2004;39:313-18.

4 Downard CD, Jaksic T, Garza JJ, et al. Analysis of an improved survival rate for congenital diaphragmatic hernia. J Pediatr Surg 2003;38:729-32.

5 Stege G, Fenton A, Jaffray B. Nihilism in the 1990s: the true mortality of congenital diaphragmatic hernia. Pediatrics $2003 ; 112(3$ pt 1):532-5.

6 Ladd WE, Gross RE. Congenital diaphragmatic hernia. N Engl J Med 1940;223:917-23.

7 Finer NN, Barrington KJ. Nitric oxide for respiratory failure in infants born at or near term (Cochrane review). Cochrane Database Syst Rev 2001;4:CD000399.

8 Bhuta T, Clark RH, Henderson-Smart DJ. Rescue high frequency oscillatory ventilation vs conventional ventilation for infants with severe pulmonary dysfunction born at or near term. Cochrane Database Syst Rev 2001; 1:CD002974.

9 Desfrere $L$, Jarreau PH, Dommergues $M$, et al. Impact of delayed repair and elective high-frequency oscillatory ventilation on survival of antenatally diagnosed congenital diaphragmatic hernia: first application of these 
strategies in the more "severe" subgroup of antenatally diagnosed newborns Intensive Care Med 2000;26:934-41.

10 Miguet D, Claris $O$, Lapillonne A, et al. Preoperative stabilization using high frequency oscillatory ventilation in the management of congenital diaphragmatic hernia. Crit Care Med 1994:22(9 suppl):S77-82

11 UK Collaborative ECMO Trial Group. UK collaborative randomised trial of neonatal extracorporeal membrane oxygenation. Lancet 1996;348:75-82.

12 Elbourne D, Field D, Mugford M. Extracorporeal membrane oxygenation for severe respiratory failure in newborn infants (Cochrane review). Cochrane Database Syst Rev 2002;1:CD001340.

13 Davis PJ, Firmin RK, Manktelow B, et al. Long-term outcome following extracorporeal membrane oxygenation for congenital diaphragmatic hernia: the UK experience. J Pediatr 2004; 144:309-15.

14 Stolar CJ. What do survivors of congenital diaphragmatic hernia look like when they grow up? Semin Pediatr Surg 1996;5:275-9.

15 Muratore CS, Kharasch V, Lund DP, et al. Pulmonary morbidity in 100 survivors of congenital diaphragmatic hernia monitored in a multidisciplinary clinic. J Pediatr Surg 2001;36:133-40.

16 Bohn D. Congenital diaphragmatic hernia. Am J Respir Crit Care Med 2002;166:911-15.

17 Wung JT, James LS, Kilchevsky E, et al. Management of infants with severe respiratory failure and persistence of the fetal circulation, without hyperventilation. Pediatrics 1985:76:488-94.

18 Wung JT, Sahni R, Moffitt ST, et al. Congenital diaphragmatic hernia: survival treated with very delayed surgery, spontaneous respiration, and no chest tube. $J$ Pediatr Surg 1995;30:406-9.

19 Moyer V, Moya F, Tibboel R, et al. Late versus early surgical correction for congenital diaphragmatic hernia in newborn infants. Cochrane Database Syst Rev 2002;3:CD001695.

20 Moss RL, Chen CM, Harrison MR. Prosthetic patch durability in congenital diaphragmatic hernia: a long-term follow-up study. J Pediatr Surg 2001;36:152-4.

21 Dalla Vecchia L, Engum S, Kogon B, et al. Evaluation of small intestine submucosa and acellular dermis as diaphragmatic prostheses. J Pediatr Surg 1999;34:167-71.

22 Arca MJ, Barnhart DC, Lelli JL Jr, et al. Early experience with minimally invasive repair of congenital diaphragmatic hernias: results and lessons learned. J Pediatr Surg 2003;38:1563-8.

23 Harrison MR, Adzick NS, Estes JM, et al. A prospective study of the outcome for fetuses with diaphragmatic hernia. JAMA 1994;271:382-4.

24 Ontario Congenital Anomalies Study Group. Apparent truth about congenital diaphragmatic hernia: a population-based database is needed to establish benchmarking for clinical outcomes for CDH. J Pediatr Surg 2004;39:661-5.

25 Javid PJ, Jaksic T, Skarsgard ED, et al. Survival rate in congenital diaphragmatic hernia: the experience of the Canadian Neonatal Network. J Pediatr Surg 2004;39:657-60.

26 Skari H, Bjornland K, Frenckner B, et al. Congenital diaphragmatic hernia: a survey of practice in Scandinavia. Pediatr Surg Int 2004;20:309-13.

27 Harrison MR, Adzick NS, Bullard KM, et al. Correction of congenital diaphragmatic hernia in utero VII: a prospective trial. J Pediatr Surg 1997;32:1637-42.

28 Wilson J, DiFiore JW, Peters CA. Experimental fetal tracheal ligation prevents the pulmonary hypoplasia associated with fetal nephrectomy: possible application for congenital diaphragmatic hernia. J Pediatr Surg 1993;28: 1433-9

29 Chiba T, Albanese CT, Farmer DL, et al. Balloon tracheal occlusion for congenital diaphragmatic hernia: experimental studies. J Pediatr Surg 2000;35:1566-70.

30 Harrison MR, Keller RL, Hawgood SB, et al. A randomized trial of fetal endoscopic tracheal occlusion for severe fetal congenital diaphragmatic hernia. N Engl J Med 2003;349:1916-24.

31 Deprest J, Gratacos E, Nicolaides KH. Fetoscopic tracheal occlusion (FETO) for severe congenital diaphragmatic hernia: evolution of a technique and preliminary results. Ultrasound Obstet Gynecol 2004;24:121-6.

32 Keller RL, Glidden DV, Paek BW, et al. The lung-to-head ratio and fetoscopic temporary tracheal occlusion: prediction of survival in severe left congenital diaphragmatic hernia. Ultrasound Obstet Gynecol 2003;21:244-9.

33 Laudy JA, Van Gucht M, Van Dooren MF, et al. Congenital diaphragmatic hernia: an evaluation of the prognostic value of the lung-to-head ratio and other prenatal parameters. Prenat Diagn 2003;23:634-9.

34 Boloker J, Bateman DA, Wung JT, et al. Congenital diaphragmatic hernia in 120 infants treated consecutively with permissive hypercapnea/spontaneous respiration/elective repair. J Pediatr Surg 2002;37:357-66.

35 Jesudason EC. Challenging embryological theories on congenital diaphragmatic hernia: future therapeutic implications for paediatric surgery. Ann R Coll Surg Engl 2002;84:252-9.

36 Keijzer R, Liu J, Deimling J, et al. Dual-hit hypothesis explains pulmonary hypoplasia in the nitrofen model of congenital diaphragmatic hernia. Am J Pathol 2000;156:1299-306.

37 Greer JJ, Babiuk RP, Thebaud B. Etiology of congenital diaphragmatic hernia: the retinoid hypothesis. Pediatr Res 2003;53:726-30.

38 van Dooren MF, Brooks AS, Tibboel D, et al. Association of congenital diaphragmatic hernia with limb-reduction defects. Birth Defects Res Part A Clin Mol Teratol 2003;67:578-84.

39 Borys D, Taxy JB. Congenital diaphragmatic hernia and chromosomal anomalies: autopsy study. Pediatr Dev Pathol 2004:7:35-8.

40 Hooper SB, Harding R. Fetal lung liquid: a major determinant of the growth and functional development of the fetal lung. Clin Exp Pharmacol Physiol 1995;22:235-47

41 Adzick NS, Harrison MR, Glick PL, et al. Experimental pulmonary hypoplasia and oligohydramnios: relative contributions of lung fluid and fetal breathing movements. J Pediatr Surg 1984; 19:658-65.

42 Smith NP, Jesudason EC, Connell MG, et al. Airway peristalsis: a novel regulator of antenatal lung growth and therapeutic target in pulmonary hypoplasia. In: British Association of Paediatric Surgeons, 2003. Portugal: Estoril, 2003

43 Adatia I. Recent advances in pulmonary vascular disease. Curr Opin Pediatr 2002; 14:292-7.

44 Losty PD, Donahoe PK, Schnitzer JJ. Prenatal hormonal therapy for pulmonary hypoplasia associated with congenital diaphragmatic hernia. Semin Neonatol 1996; 1:193-202

45 The Congenital Diaphragmatic Hernia Study Group. Estimating disease severity of congenital diaphragmatic hernia in the first 5 minutes of life. The Congenital Diaphragmatic Hernia Study Group. J Pediatr Surg $2001 ; 36: 141-5$. 